\begin{tabular}{|c|c|c|c|}
\hline \multirow{3}{*}{$\begin{array}{r}\text { Case Reports in } \\
\text { Gastroenterology }\end{array}$} & \multirow{2}{*}{\multicolumn{2}{|c|}{ Case Rep Gastroenterol 2019;13:258-264 }} & \multirow[b]{3}{*}{$\begin{array}{l}\text { Karger } \\
\text { Open access }\end{array}$} \\
\hline & & & \\
\hline & $\begin{array}{l}\text { DOI: } 10.1159 / 000501068 \\
\text { Published online: June } 13,2019\end{array}$ & $\begin{array}{l}\text { (c) } 2019 \text { The Author(s) } \\
\text { Published by S. Karger AG, Basel } \\
\text { www.karger.com/crg }\end{array}$ & \\
\hline & $\begin{array}{l}\text { This article is licensed under } t \\
\text { International License (CC BY-N } \\
\text { Usage and distribution for comm }\end{array}$ & $\begin{array}{l}\text { mons Attribution-NonCommercial } 4.0 \\
\text { rger.com/Services/OpenAccessLicense). } \\
\text { quires written permission. }\end{array}$ & \\
\hline
\end{tabular}

\title{
Pulmonary Embolism in a Donor of Living Donor Liver Transplantation
}

\author{
Shinji Onda Hiroaki Shiba Taro Sakamoto Kenei Furukawa \\ Takeshi Gocho Katsuhiko Yanaga \\ Department of Surgery, The Jikei University School of Medicine, Tokyo, Japan
}

\section{Keywords}

Postoperative venous thromboembolism · Living donor liver transplantation .

Life-threatening complication

\begin{abstract}
Pulmonary embolism (PE) is a rare but potentially fatal complication that may develop in a living liver donor. Here, we report a case of non-massive PE diagnosed by elevated serum D-dimer levels and successfully treated using anticoagulant therapy. A 57-year-old man underwent extended left hepatectomy as a living liver donor. His past medical history included hypertension and dyslipidemia which required medication and a history of smoking. Mechanical prophylactic measures for venous thromboembolism, including intermittent pneumatic compression and elastic stocking, were used; however, no pharmacological prophylaxis was used. Although the patient ambulated on postoperative day (POD) 1, he developed hypoxia. Serum D-dimer level was elevated to $29.3 \mathrm{ng} / \mathrm{mL}$ on POD 2. Enhanced computed tomography revealed small peripheral PEs in the branches of the right upper, right middle, and left lower lobes without deep vein thrombosis. Intravenous heparin was initiated followed by warfarin. The thrombi resolved completely by POD 13, following which warfarin was continued for 3 months. As of 25 months after donation, the patient remains well without recurrence of PE. Early diagnosis and treatment of postoperative PE are critical for preventing mortality of liver donors.

(C) 2019 The Author(s)

Published by S. Karger AG, Basel
\end{abstract}




\section{Introduction}

Liver transplantation has been extensively performed worldwide as the sole curative treatment for end-stage liver diseases. Living donor liver transplantation (LDLT) is more extensively practiced in several Asian countries than in Western countries [1]. In LDLT, the donor must be carefully selected and evaluated before donation. Donor safety is the highest priority and requires special attention because the donation surgery is performed on a healthy individual. Although the risks for complications directly associated with surgical intervention have been carefully evaluated for such donors, nonsurgical complications, such as occurrence of pulmonary embolism (PE) associated with living donation, cannot be clearly anticipated. Postoperative PE in general has been recognized as the significant source of morbidity and mortality in recent years [2].

Here, we report a case of PE wherein the patient underwent extended left hepatectomy as a LDLT donor.

\section{Case Presentation}

A 57-year-old man was evaluated for living liver donation for his wife with end-stage liver disease due to primary biliary cholangitis. His medical history included hypertension and dyslipidemia that was treated with azelnidipine $16 \mathrm{mg}$ p.o. once daily and pravastatin $10 \mathrm{mg}$ once daily. No family history of thrombosis was noted. The patient had a past history of smoking 20 cigarettes per day for 18 years but had discontinued 20 years ago. His height and weight were $166 \mathrm{~cm}$ and $60 \mathrm{~kg}(\mathrm{BMI}=21.8)$, respectively, and his physical examination was unremarkable. In order to avoid homologous blood transfusion, a total of $800 \mathrm{~mL}$ of autologous blood was stored prior to liver donation. Following the autologous blood donation, his blood test results were as follows: hemoglobin $12.1 \mathrm{~g} / \mathrm{dL}$, platelets $190 \times 10^{3} / \mathrm{L}$, prothrombin time (PT) $>100 \%$, international normalized ratio (INR) $<1.0$, fibrinogen $306 \mathrm{mg} / \mathrm{dL}$, D-dimer $<0.2 \mathrm{ng} / \mathrm{mL}$, and antithrombin III (AT III) $122 \%$. The indocyanine green retention rate was $9 \%$. He underwent extended left hepatectomy, including the middle hepatic vein and caudate lobe, as well as cholecystectomy. The operation was uneventful and the operation time was $552 \mathrm{~min}$. The intraoperative blood loss was $200 \mathrm{~mL}$, and $400 \mathrm{~mL}$ of autologous red blood cells was transfused. Consequently, the intraoperative fluid balance was positive, exceeding 2,680 mL. Intermittent pneumatic compression and elastic stocking were used during and after surgery, respectively. Pharmacological venous thromboembolism (VTE) prophylaxis was not used. The patient ambulated on postoperative day (POD) 1, when he developed hypoxia with an oxygen saturation level of approximately $90 \%$ on room air, requiring $1 \mathrm{~L} / \mathrm{min}$ of oxygen via a nasal cannula; his vital signs were stable. The serum D-dimer level was elevated to $21.2 \mathrm{ng} / \mathrm{mL}$ and further increased to $29.3 \mathrm{ng} / \mathrm{mL}$ on POD 2. Enhanced computed tomography (CT) performed on POD 2 revealed small peripheral PEs in the branches of the right upper, right middle, and left lower lobes without deep vein thrombosis (Fig. 1). The electrocardiogram result was normal, and echocardiography demonstrated normal cardiac function. He was diagnosed with non-massive PE and continuous heparin infusion was initiated. The AT III and protein $\mathrm{C}$ and $\mathrm{S}$ activity levels were within the normal range before initiating anticoagulation. Subcutaneous hemorrhage was observed at the abdominal incision site following the heparin administration. Consequently, the heparin dose was adjusted to maintain APTT at approximately $50 \mathrm{~s}$. Follow-up enhanced CT performed on POD 7 revealed that the thrombi in the branches of the right upper and right middle lobes had resolved, whereas those in the 
branches of the left lower lobe had increased in size (Fig. 2). The heparin dose was increased to maintain an APTT of approximately $70 \mathrm{~s}$. The thrombi showed complete resolution by CT on POD 13; however, a new hematoma developed adjacent to the liver transection plane without development of anemia (Fig. 3). Subsequently, warfarin was initiated to maintain the PTINR between 1.5 and 2.5, and intravenous heparin was discontinued once the PT-INR reached therapeutic levels. CT performed on POD 21 showed no evidence of PE and no enlargement of the intra-abdominal hematoma, and the patient was discharged on POD 22. Warfarin was continued for 3 months and then discontinued. At 25 months after donation, the patient remains well without recurrence of PE.

\section{Discussion}

According to a worldwide survey, the incidence of mortality in liver donors following LDLT was $0.18-0.2 \%$ [3, 4]. In Japan, as of 2013, a total of 7,255 LDLTs have been performed, wherein one donor death related to liver donation has been reported [5]. PE is a well-known and potentially fatal complication that may develop following LDLT. Several cases of PE following liver donation have been reported in the literature, wherein at least four of the patients have died [6-11]. Therefore, appropriate risk screening and prophylaxis for VTE are crucial for reducing the risk of fatal PE in donors.

At our institution, we have conventionally measured platelet count, PT, and APTT as well as serum fibrinogen and D-dimer levels in donor candidates for thrombophilia screening. However, these are insufficient in determining donor candidates who must be excluded or require anticoagulants for prophylaxis. For the accurate evaluation of thrombophilia, the measurements of additional parameters, such as proteins S and C, AT III, and antiphospholipid antibodies, are necessary. The prevalence of hereditary deficiencies of natural anticoagulants, such as AT III and proteins C and S, in healthy individuals is substantially low; however, in healthy individuals with these deficiencies, the risk of VTE following surgery is considerably higher than in normal healthy individuals. In addition, a previous history of VTE is one of the most significant risk factors for postoperative VTE [12]. Therefore, we believe that these patients should be excluded from being donor candidates.

As prophylaxis for VTE for donors, we routinely use elastic stocking and intermittent pneumatic compression in addition to early ambulation following surgery. Liver resection is associated with a postoperative hypercoagulable state that can lead to the development of VTE. However, because of the risk of posttransplant hemorrhage and the lack of evidence of anticoagulant prophylaxis in liver surgery, prophylactic anticoagulant therapy following donation is not routinely performed. Nevertheless, several studies have recently reported the safety and efficacy of pharmacological thromboprophylaxis in liver surgery $[13,14]$. A recent study on the risk stratification approaches for VTE prophylaxis based on thrombophilia test results in a large cohort of LDLT donors revealed its necessity and usefulness [15].

Early diagnosis and treatment of postoperative PE are essential for a successful outcome. We routinely measure the serum D-dimer levels on PODs 1, 3, 5, and 7. In cases where the serum D-dimer level is elevated to $\geq 20 \mathrm{ng} / \mathrm{mL}$, regardless of the absence of clinical symptoms, enhanced CT is performed primarily to rule out PE or other VTE. In the present case, the diagnosis of PE was immediately made using CT, which was performed for hypoxia associated with elevated serum D-dimer level. Based on our experience, we advocate routine measurement of serum D-dimer level following hepatectomy. 
Anticoagulant therapy was initiated on POD 2, although the heparin dose was reduced because of subcutaneous bleeding. After the bleeding had subsided, the dose was increased and PE was resolved. Management of anticoagulant therapy following hepatectomy is challenging because the patients typically develop transient liver dysfunction postoperatively, with a coagulation factor imbalance that can cause postoperative bleeding.

In conclusion, we report a case of PE diagnosed by elevated serum D-dimer level, and the patient was successfully treated with anticoagulant therapy. Although PE is a rare complication in LDLT donors, it can be potentially fatal. Clinicians should be aware of the possibilities of this complication. Early diagnosis and treatment using serum D-dimer testing and CT are critical for preventing mortality.

\section{Statement of Ethics}

The authors have no ethical conflicts to disclose. Written informed consent was obtained from the patient.

\section{Disclosure Statement}

The authors have no conflicts of interest to declare.

\section{Funding Sources}

None of the authors has anything to disclose.

\section{Author Contributions}

S. Onda: collection of data and drafting of the manuscript. H. Shiba: collection of data and revision of the manuscript. T. Sakamoto, K. Furukawa, and T. Gocho: collection of data. K. Yanaga: critical revision of the manuscript. All authors read and approved the final manuscript.

\section{References}

1 Lo CM. Complications and long-term outcome of living liver donors: a survey of 1,508 cases in five Asian centers. Transplantation. 2003 Feb;75(3 Suppl):S12-5.

2 Gould MK, Garcia DA, Wren SM, Karanicolas PJ, Arcelus JI, Heit JA, et al. Prevention of VTE in nonorthopedic surgical patients: antithrombotic therapy and prevention of thrombosis, 9th ed: American College of Chest Physicians Evidence-Based Clinical Practice Guidelines. Chest. 2012 Feb;141(2 Suppl):e227S-77S.

3 Adam R, Karam V, Delvart V, O'Grady J, Mirza D, Klempnauer J, et al.; All contributing centers (www.eltr.org); European Liver and Intestine Transplant Association (ELITA). Evolution of indications and results of liver transplantation in Europe. A report from the European Liver Transplant Registry (ELTR). J Hepatol. 2012 Sep;57(3):675-88.

4 Cheah YL, Simpson MA, Pomposelli JJ, Pomfret EA. Incidence of death and potentially life-threatening nearmiss events in living donor hepatic lobectomy: a world-wide survey. Liver Transpl. 2013 May;19(5):499506. 


\section{Case Reports in Gastroenterology}

\begin{tabular}{|l|l|}
\hline DOI: 10.1159/000501068 & (c) 2019 The Author(s). Published by S. Karger AG, Basel \\
\hline
\end{tabular}
www.karger.com/crg

Onda et al.: Pulmonary Embolism in a Living Liver Donor

5 Umeshita K, Fujiwara K, Kiyosawa K, Makuuchi M, Satomi S, Sugimachi K, et al.; Japanese Liver Transplantation Society. Operative morbidity of living liver donors in Japan. Lancet. 2003 Aug; 362(9385):687-90.

6 Özbilgin M, Ünek T, Egeli T, Ağalar C, Ozkardesler S, Karadeniz E, et al. Complications in donors using right liver graft: analysis of 280 consecutive cases. Transplant Proc. 2017 Apr;49(3):580-6.

7 Broering DC, Wilms C, Bok P, Fischer L, Mueller L, Hillert C, et al. Evolution of donor morbidity in living related liver transplantation: a single-center analysis of 165 cases. Ann Surg. 2004 Dec;240(6):1013-24; discussion 1024-6.

8 Durand F, Ettorre GM, Douard R, Denninger MH, Kianmanesh A, Sommacale D, et al. Donor safety in living related liver transplantation: underestimation of the risks for deep vein thrombosis and pulmonary embolism. Liver Transpl. 2002 Feb;8(2):118-20.

9 Trotter JF, Adam R, Lo CM, Kenison J. Documented deaths of hepatic lobe donors for living donor liver transplantation. Liver Transpl. 2006 Oct;12(10):1485-8.

10 Lauterio A, Di Sandro S, Gruttadauria S, Spada M, Di Benedetto F, Baccarani U, et al. Donor safety in living donor liver donation: an Italian multicenter survey. Liver Transpl. 2017 Feb;23(2):184-93.

11 Onur A, Akbulut S, Dirican A, Isik B, Yilmaz S. Life-threatening or nearly life-threatening complications in living liver donors. Clin Transplant. 2018 Jun;32(6):e13262.

12 Gonzalez R, Haines K, Nelson LG, Gallagher SF, Murr MM. Predictive factors of thromboembolic events in patients undergoing Roux-en-Y gastric bypass. Surg Obes Relat Dis. 2006 Jan-Feb;2(1):30-5; discussion 35-6.

13 Kim BJ, Day RW, Davis CH, Narula N, Kroll MH, Tzeng CW, et al. Extended pharmacologic thromboprophylaxis in oncologic liver surgery is safe and effective. J Thromb Haemost. 2017 Nov; 15(11):2158-64.

14 Reddy SK, Turley RS, Barbas AS, Steel JL, Tsung A, Marsh JW, et al. Post-operative pharmacologic thromboprophylaxis after major hepatectomy: does peripheral venous thromboembolism prevention outweigh bleeding risks? J Gastrointest Surg. 2011 Sep;15(9):1602-10.

15 Kamei H, Onishi Y, Kurata N, Ishigami M, Ogura Y. Donor selection and prophylactic strategy for venous thromboembolic events in living donors of liver transplantation based on results of thrombophilia screening tests. Ann Transplant. 2017 Jul;22:409-16. 


\section{Case Reports in Gastroenterology}

\begin{tabular}{l|l}
\hline Case Rep Gastroenterol 2019;13:258-264 \\
\hline DOI: 10.1159/000501068 & $\begin{array}{l}\text { c 2019 The Author(s). Published by S. Karger AG, Basel } \\
\text { www.karger.com/crg }\end{array}$ \\
\hline
\end{tabular}

Onda et al.: Pulmonary Embolism in a Living Liver Donor
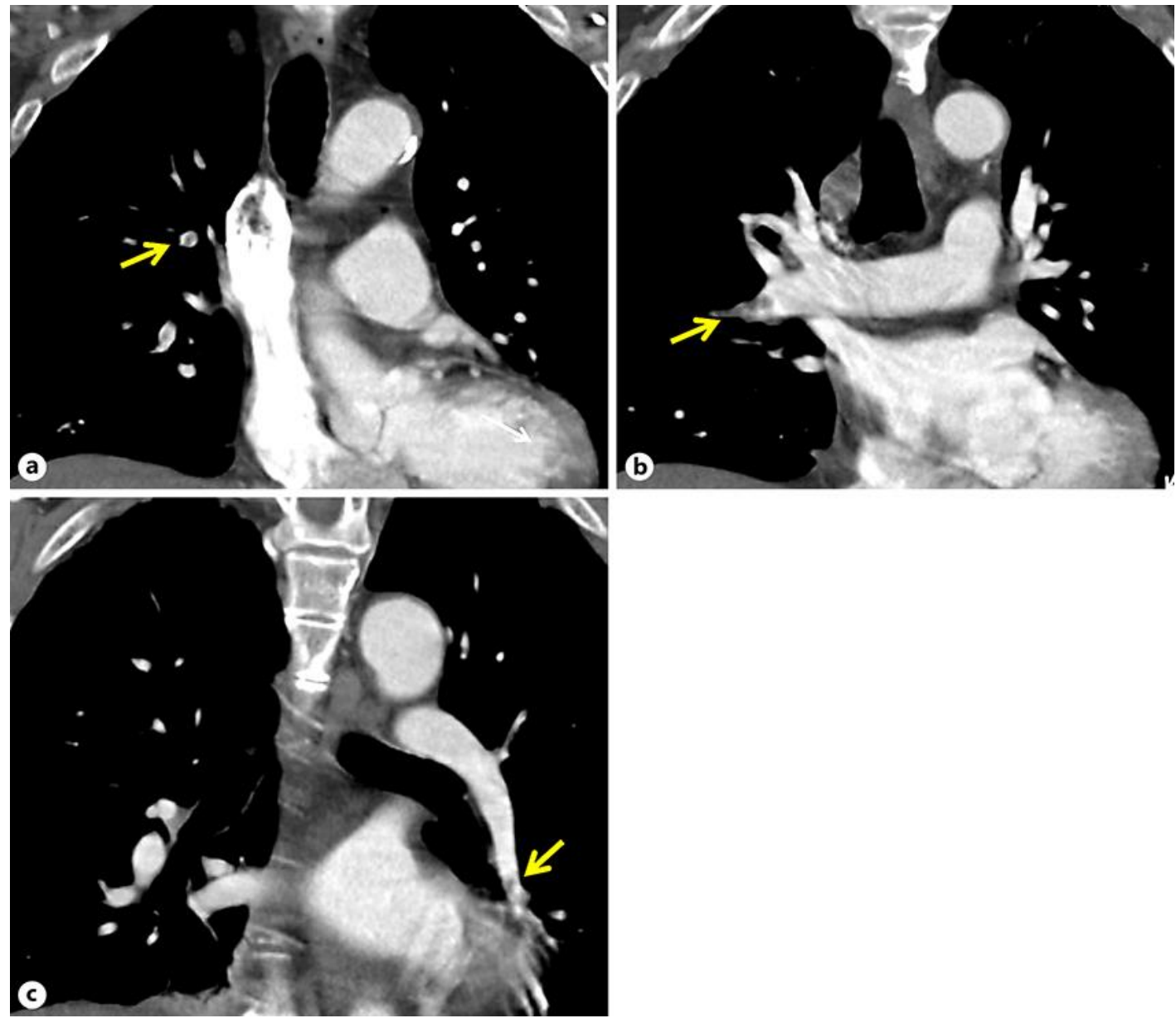

Fig. 1. Enhanced CT revealed small peripheral pulmonary embolisms in the branches of the right upper (a, arrow), right middle (b, arrow), and left lower (c, arrow) lobes without deep vein thrombosis.
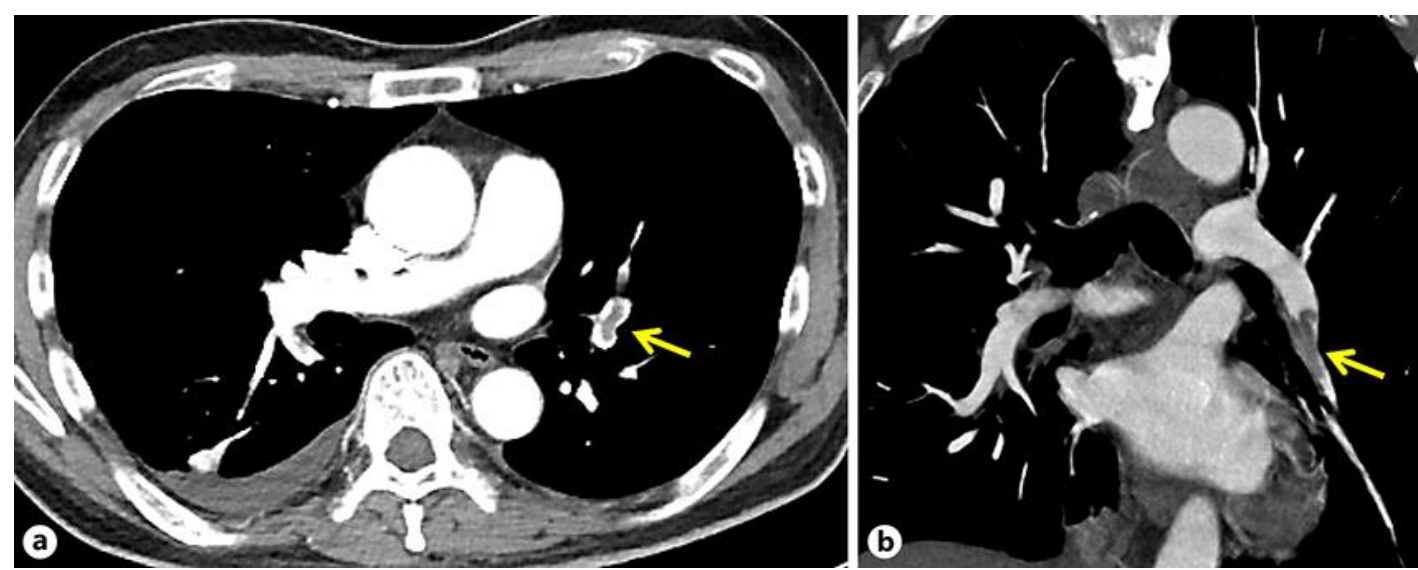

Fig. 2. Follow-up enhanced computed tomography performed on postoperative day 7 revealed that the thrombi in the branches of the right upper and right middle lobes had resolved, but those in the branches of the left lower lobe had increased in size (arrows) (a axial, b frontal). 

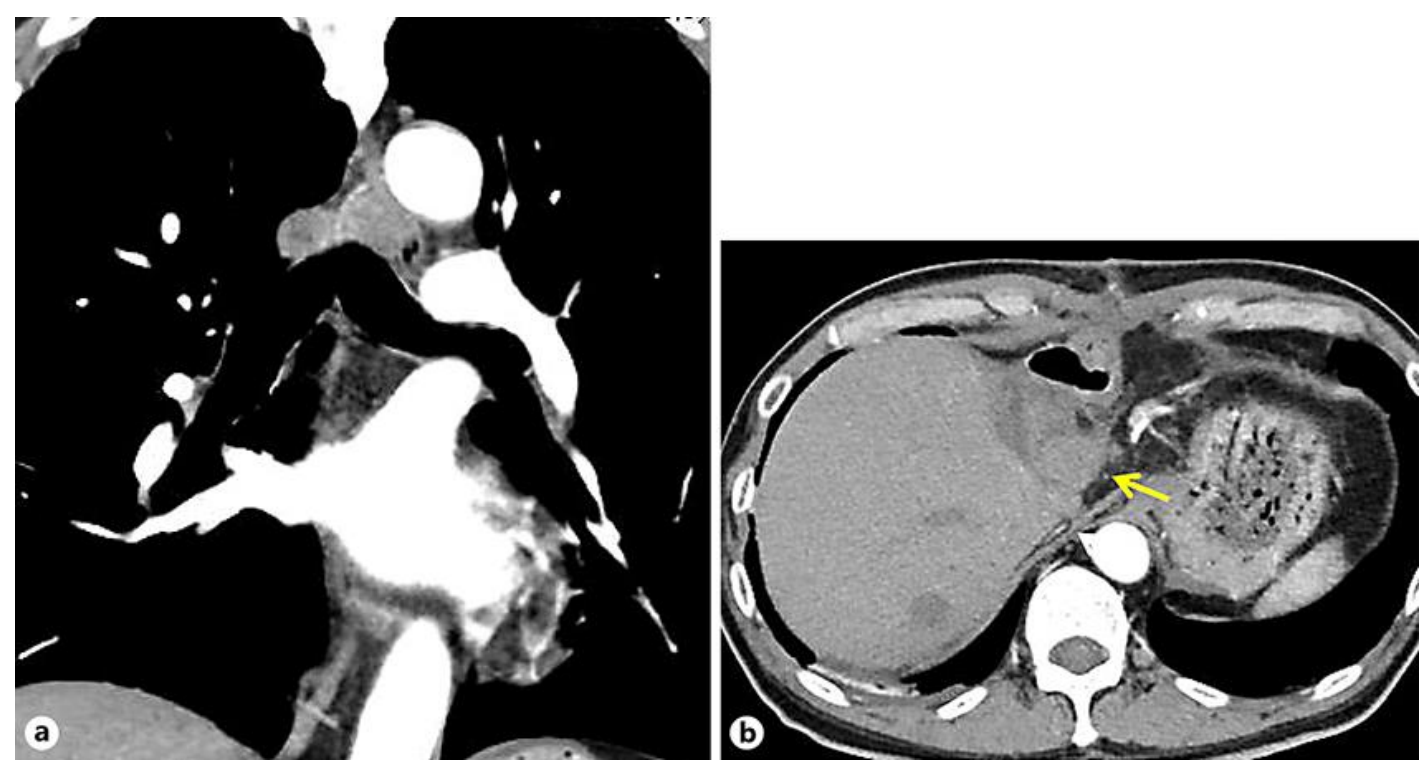

Fig. 3. Computed tomography performed on postoperative day 13 revealed complete resolution of the thrombi (a); however, a hematoma had developed next to the liver stump (b, arrow). 